\title{
Social Dimensions of Musculoskeletal Pain Experiences among the Elderly in Southwestern Nigeria
}

\author{
Matthew Ayegboyin, Kabiru K. Salami* \\ Department of Sociology, University of Ibadan, Ibadan, Nigeria \\ Email: *kabsalami@yahoo.co.uk
}

How to cite this paper: Ayegboyin, M. and Salami, K.K. (2019) Social Dimensions of Musculoskeletal Pain Experiences among the Elderly in Southwestern Nigeria. Health, 11, 953-970.

https://doi.org/10.4236/health.2019.117077

Received: April 15, 2019

Accepted: July 27, 2019

Published: July 30, 2019

Copyright $\odot 2019$ by author(s) and Scientific Research Publishing Inc. This work is licensed under the Creative Commons Attribution International License (CC BY 4.0).

http://creativecommons.org/licenses/by/4.0/

Open Access

\begin{abstract}
Musculoskeletal pain (MS pain) in the elderly has attracted more medical focus than its social dimensions. This cross-sectional survey design study, conducted in southwestern Nigeria, through a multi-stage sampling technique, documented reported MS pain in 1280 consented elderly using 3-scale pain experiences categorized as acute, semi-acute, and chronic. Also, 12 In-depth Interviews (IDIs) among elderly persons, and 15 Key Informant Interviews (KIIs) among orthodox- and traditional medicine practitioners were conducted. The age of the respondents was $65.5 \pm 4$, while about half (51.1\%) had no formal education. Majority (76.8\%) of the respondents perceived MS pain as normal process of old age. Occupational life history of the respondents ranked the highest as perceived reason for having MS pain, while the knees (19.6\%) were the most identified pained location among others in the body. A high significant relationship between neck and shoulders pain $\left(\chi^{2}=0.000\right)$ was however found. Social construction dimensions of the elderly were narrated, while MS pain was considered as sickness of the elders. There is need for orientation for the elderly and their helpers on the social dimensions of old age relative to Nigeria.
\end{abstract}

\section{Keywords}

Ageing Population, Older Persons, Musculoskeletal Pain, Social Dimensions, Social Security

\section{Introduction}

Musculoskeletal pain, a non-communicable disease, which contributes to years lived with disability (YLD) among individuals, accounted for high mortality in sub-Saharan Africa [1]. The elderly or older adults as the case maybe have been 
considered the most at risk of experiencing musculoskeletal conditions in society [2]. Musculoskeletal pain ranks high as most health challenge of the elderly and it is estimated that about $60 \%$ to $80 \%$ of the people above 60 years experienced at least some levels of chronic pain globally [3]. The health of the aged people in Nigeria has great impact on the aging population in sub-Saharan Africa [4]. In spite of this, Nigeria has still not initiated a concrete national policy for the care of the elderly [5]. For people to grow old peacefully and gracefully, the health of the elderly must be taken into cognizance as it has influence on active aging, while the impact of musculoskeletal pain among elderly depends on individual biological, psychological, social and demographic factors [6]. The National Academy of Science [7] posits that biological factors that can cause pain include composition of sex, genetics to injuries, diseases and pain receptors in the body. The psychological factors that contribute to pain include fear of pain, anger, depression, and emotional stress among others. However, social factors which influence pain experiences include inability to communicate pain, cultural norms, demands of the work environment, access to medical care, family attitudes and cultural beliefs [7].

The risk of musculoskeletal pain is affected by demographic factors such as sex, income, education, ethnic group, urban or rural living and age group [8]. Some other factors that contribute to pain may include prolonged sitting, poor postures, exposure to whole-body vibration, long driving time, heavy lifting, manual materials handling, poor diet [9] [10], obesity, and lack of physical activity [11]. Musculoskeletal pain has no age-restriction, hence, children, teenagers, adults as well as pregnant women also experience pains, however, it is more intense among the elderly. Epidemiologically, about $21 \%$ of the population below age 60 face challenges of chronic pain globally [1] [12]. Evidence has however shown that musculoskeletal pain grows with age and about $75 \%$ of elderly people globally experience persistent pain [13].

As observed [14], the pain experience by individuals could be more terrible than death itself and many people still die from avoidable musculoskeletal pain, NICE [8] also noted that most elderly still perceive musculoskeletal pain experience as normal aging process due to bodily "wear and tear". Significantly, the major causes of musculoskeletal pain among elderly are varied [1] and may include a result of disorders in the bone, joints, muscles, tendons, ligaments or a combination of these disorders and injuries sustained over time [15]. Life course trajectory can also promote the way elderly feel pain. For instance, musculoskeletal pain conditions among retired military personnel are significantly worse than the experiences of the general public [16].

The turning points of the elderly could also attract adverse health and social effects on the elderly and their generations [17]. Experiences of the elders such as health challenges from musculoskeletal pain without adequate care may reduce their performance [18] as custodians of information and wisdom as well as great resources for younger generations [19] at household and societal levels. 
Aging stage can actually push the elderly out of their sources of income as they are less active in their economic contribution to their workplace yet the elderly medical expenses tend to rise at that time [20]. Hence, agbalagba (the noble aged) can become agbalangba (the ignoble aged) retrogressively, as observed by Omobowale [21]. However, most elderly in Nigeria are unable to carter for their health needs, while comprehensive free health care services are unavailable specifically for the elderly population in Nigeria [22].

Musculoskeletal pain experiences limit physical activity of older adults and may lead to a cycle of restriction, decreased participation in social engagement and meaningful activities, increased body weight and disability status [23]. The impact of such experiences may also lead to chronic problems in initiating and maintaining sleep, a direct link to increase in depression and suicidal ideation in older people. Chronic musculoskeletal pain experience was observed a major contributor to falls, while falls is a major cause of death among the elderly globally [24]. Besides, the elderly also experienced other social issues such as loneliness, and discrimination after retirement, hence having negative impact on peaceful aging. This study examined the social dimensions of musculoskeletal pain among elderly of Southwestern, Nigeria.

\section{Methods and Materials}

\subsection{Study Area}

This study, conducted in Oyo State, located in Southwestern geopolitical zone of Nigeria, lies on latitude 8 degree and longitude 4 degree east. The State is bound in the south by Ogun State and partially by the Republic of Benin, in the east by Osun State and in the north by Kwara State. It covers 27,249 square kilometres landmass with total population of 5,580,894 and with elderly population of 327,301 shared into 172,547 males and 154,754 females [25]. The State has thirty-three local government areas (LGAs) which fall into three senatorial districts vis-à-vis Oyo Central, Oyo North and Oyo South. Oyo Central Senatorial District has 11 LGAs, Oyo North Senatorial District consists of 13 LGAs, while Oyo South Senatorial District has 9 LGAs.

\subsection{Study Design and Sampling Procedure}

This was a cross-sectional survey design which utilised triangulation of quantitative and qualitative methods. This study was conducted between July and September, 2017 among the elderly who had attained a minimum age of 60 years. For the quantitative method, multi-stage sampling technique was employed to select Oyo State which has the highest elderly population $(327,296)$ in the southwest zone of Nigeria. With 33 LGAs in the State, all the LGAs were clustered into the three senatorial districts from which nine (9) LGAs (Afijio, Atisbo, Ibadan South-East, Lagelu, Iwajowa, Ibadan North-West, Oyo East, Olorunsogo, and Ido) were selected for questionnaire administration. The total sample size for this was 1320 elderly people who attained 60 years as at the time 
of the survey and at the same time had experienced continuous MS pain for at least up to thirty days as inclusion criteria for this study. Although 1320 copies of a pretested questionnaire were administered among the elderly, only 1280 copies were adequate for the study analysis at $97.0 \%$ returned rate.

In-depth interview (IDI) was conducted among selected elderly and key informant interview (KII) was conducted among health officers, patent medicine vendours (PMVs) and traditional healers. The selection of LGAs for the IDI sessions was based on the three selected LGAs meant for the quantitative data. After the full administration of questionnaire in all the three selected LGAs, effort was made, through balloting, to identify 2 elderly men and 2 elderly women who reportedly experienced acute MS pain and chronic MS pain during the course of questionnaire administration. These selected elderly formed the participants for the IDI.

\subsection{Data Collection Procedures}

This study used pretested interviewer-administered questionnaire, in-depth interview (IDI) and key informant interview (KII) guides. Data were collected by eight trained research assistants and two supervisors who are versatile in social research. All the field staff were trained on the use of the instruments for data collection, how to locate study areas, identification of eligible participants, and how to operate digital tape for recording and transcription. At the end of the training, the instruments for data collection were pretested in a local government that was not listed for final data collection. At the end, those questions that were either not well worded, or sounded confusing and not clear to respondents were removed. Some questions that were repeated were also eliminated. Being a larger study, the questionnaire used has 11 sections (sections $A-K$ ) that addressed; sociodemographic information of respondents, perceived causes of MS pain, patterns of MS pain, effect of MS pain, illness behaviour of the elderly, and health-seeking pathways. Other sections addressed; treatment sources of MS pain, decision making process, sedentary behaviours and MS pain, and social supports for the elderly. All the administered copies of questionnaire for each day were collated by the researchers; questionnaire was cross-checked and correction was made where necessary. The duly cleaned copies of the questionnaire were locked up in a safe place where only the researchers had access. For proper documentation of IDI and KII sessions, each of the sessions was anchored by a moderator and a note taker. Each interview was properly recorded to ensure accurate transcription and interpretation.

\subsection{Ethical Consideration}

Ethical principles governing human research was observed at all stages of the research. For instance, consent of all the respondents was sought for their participation, participants were made to know the main focus of the research, they were made to know that participation was voluntary and that they were at liberty 
to discontinue with the interview at any time they so desire. All these were in addition to ethical approval sought from the University of Ibadan Social Sciences and Humanity Ethical Review Committee.

\subsection{Data Management and Analysis}

Quantitative data were entered into the computer for analysis. Statistical analyses of the quantitative data were conducted using chi-square tests at $95 \%$ level of significance. Chi-square, which is non-parametric test of statistical significance for bivariate tabular analysis, was used to know whether or not two different samples have significant relationship. The qualitative data was analysed thematically [26] using Atlas.ti 6.2 software. Braun and Clarke (2006) suggested thematic analysis as relevant "when investigating an under-researched area, or while working with participants whose views on a particular topic are not known". The thematic approach was engaged with analytical rigour [27] after which nodes were exported from Atlas.ti software to a word document, read several times to identify the emerging patterns, and finally arrived at the meanings that emerged from the key themes.

\section{Results}

\subsection{Socio-Demographic Characteristics of Respondents}

The age distribution analysis indicated that half $(50.1 \%)$ of the respondents fell between age 60 and 69 years. Table 1 shows that 5.4\% respondents were above 89 years old. Female respondents were a little above average (56.4\%) than the male counterpart. Majority (65.4\%) of the respondents were Muslims and only $3.3 \%$ practiced traditional religion. The marital status analysis indicated that large majority $(74.6 \%)$ of the respondents had spouses, of which, $32.8 \%$ reportedly maintained their only spouses, while $31.8 \%$ of the respondents live with spouses re-married to. Distribution of family members living with the respondents revealed that $23.4 \%$ respondents had their own children alone living with them, $12.0 \%$ respondents had their grandchildren living with them, while $16.0 \%$ respondents had none of their family members living with them. Data indicated a minimum of three children each living with $84.3 \%$ respondents or a maximum of seven children each living with $1.4 \%$ respondents as shown in Table 1.

\subsection{Socio-Economic and Health Expenditure Status of the Respondents}

The socio-economic data of the respondents revealed that about half (51.1\%) did not have any formal educational qualification. The residential ownership data showed that two-fifth (41.6\%) of the respondents lived in houses built by themselves and $16.6 \%$ respondents reportedly lived in the houses owned by their spouse. Meanwhile, $15.5 \%$ of the respondents lived in the family house, while one-twelfth $(7.9 \%)$ respondents inherited the house they lived in. Majority $(65.3 \%)$ of the respondents were self-employed, while $26.0 \%$ respondents were 
Table 1. Socio-demographic characteristics of the respondents $(\mathrm{N}=1280)$.

\begin{tabular}{|c|c|c|c|}
\hline & Variables & Frequency & Percentage \\
\hline \multirow{4}{*}{ Age distributions } & $60-69$ & 641 & 50.1 \\
\hline & $70-79$ & 424 & 33.1 \\
\hline & $80-89$ & 146 & 11.4 \\
\hline & 90 and Above & 69 & 5.4 \\
\hline \multirow{2}{*}{ Sex } & Female & 722 & 56.4 \\
\hline & Male & 558 & 43.6 \\
\hline \multirow{3}{*}{ Religious affiliations } & Islam & 837 & 65.4 \\
\hline & Christianity & 412 & 32.2 \\
\hline & Traditional & 31 & 3.3 \\
\hline \multirow{5}{*}{ Marital status } & Married to current spouse only & 420 & 32.8 \\
\hline & Re-married to current spouse & 407 & 31.8 \\
\hline & Widowed & 357 & 27.9 \\
\hline & Divorced/separated & 75 & 5.9 \\
\hline & Unmarried & 21 & 1.6 \\
\hline \multirow{7}{*}{$\begin{array}{l}\text { Current family living } \\
\text { with }\end{array}$} & Children & 300 & 23.4 \\
\hline & Spouse(s) \& Children & 193 & 15.1 \\
\hline & Children \& Grand children & 164 & 12.8 \\
\hline & Grand children & 153 & 12.0 \\
\hline & Spouse(s) & 150 & 11.7 \\
\hline & Others & 115 & 9.0 \\
\hline & None & 205 & 16.0 \\
\hline \multirow{3}{*}{$\begin{array}{l}\text { Number of children } \\
\text { living with }\end{array}$} & $1-3$ & 649 & 84.3 \\
\hline & $4-6$ & 110 & 14.3 \\
\hline & Above 6 & 11 & 1.4 \\
\hline \multirow{2}{*}{$\begin{array}{l}\text { Marital family of } \\
\text { orientation }\end{array}$} & Polygyny & 842 & 65.8 \\
\hline & Monogamy & 438 & 34.2 \\
\hline \multirow{2}{*}{$\begin{array}{l}\text { Marital family of } \\
\text { procreation }\end{array}$} & Polygyny & 716 & 55.9 \\
\hline & Monogamy & 564 & 44.1 \\
\hline \multirow{3}{*}{ Household headship } & Self & 934 & 73.0 \\
\hline & Spouse & 258 & 20.2 \\
\hline & Children & 88 & 6.9 \\
\hline \multirow{4}{*}{ Parental status } & None alive & 1129 & 88.2 \\
\hline & Both parents alive & 64 & 5.0 \\
\hline & Only mothers alive & 62 & 4.8 \\
\hline & Only fathers alive & 25 & 2.0 \\
\hline \multirow{2}{*}{ Caregivers around } & Family members & 1199 & 93.7 \\
\hline & Non-family members & 81 & 6.3 \\
\hline
\end{tabular}

not working. The average monthly income received by the respondents working as at time of this study indicated that about four-fifth (80.8\%) respondents re- 
ceived less than thirty thousand naira (N30,000), while only $2.6 \%$ of the respondents received sixty thousand naira and above $(\mathrm{N} 60,000)$ per month. When respondents were asked to indicate other sources of financial supports, the large majority $(79.1 \%)$ who received money through other sources reportedly got the money; from their grown up children $(71.2 \%)$, religious associates they maintained $(8.1 \%)$ and through pension $(0.8 \%)$ as their source of getting money.

The health expenditure of the respondents was documented. The respondents reportedly foot the expenses on the health of the spouse (36.6\%), children (41.8\%) and personal medical bill (86.3\%). The monthly expenditure on pain-relief drugs costed between five thousand Naira (N5000.00) and slightly above ten thousand Naira (N10,000.00). A large majority (84.8\%) of respondents had never known about health insurance Scheme and almost all (98.7\%) respondents did not plan to enrol with any of health insurance schemes.

\subsection{Yoruba Categorisation of Elderly}

The respondents were made to categorise the elderly for easy description of the dimensions of MS pain. In this study, the elderly were categorised into four age groups of; $60-69$ years, $70-79$ years, $80-89$ years and $89+$ years as shown in Figure 1. The elderly of age 60 - 69 years was described as young elderly ( $\mathrm{Agba}$ ) by $27.5 \%$ respondents, and $25.2 \%$ respondents categorised age $70-79$ years as old elderly (Agbalagba). Also, 24.5\% respondents categorised elderly of age 80 89 years as older elderly (Arugbo), while $22.8 \%$ respondents described age $89+$ as

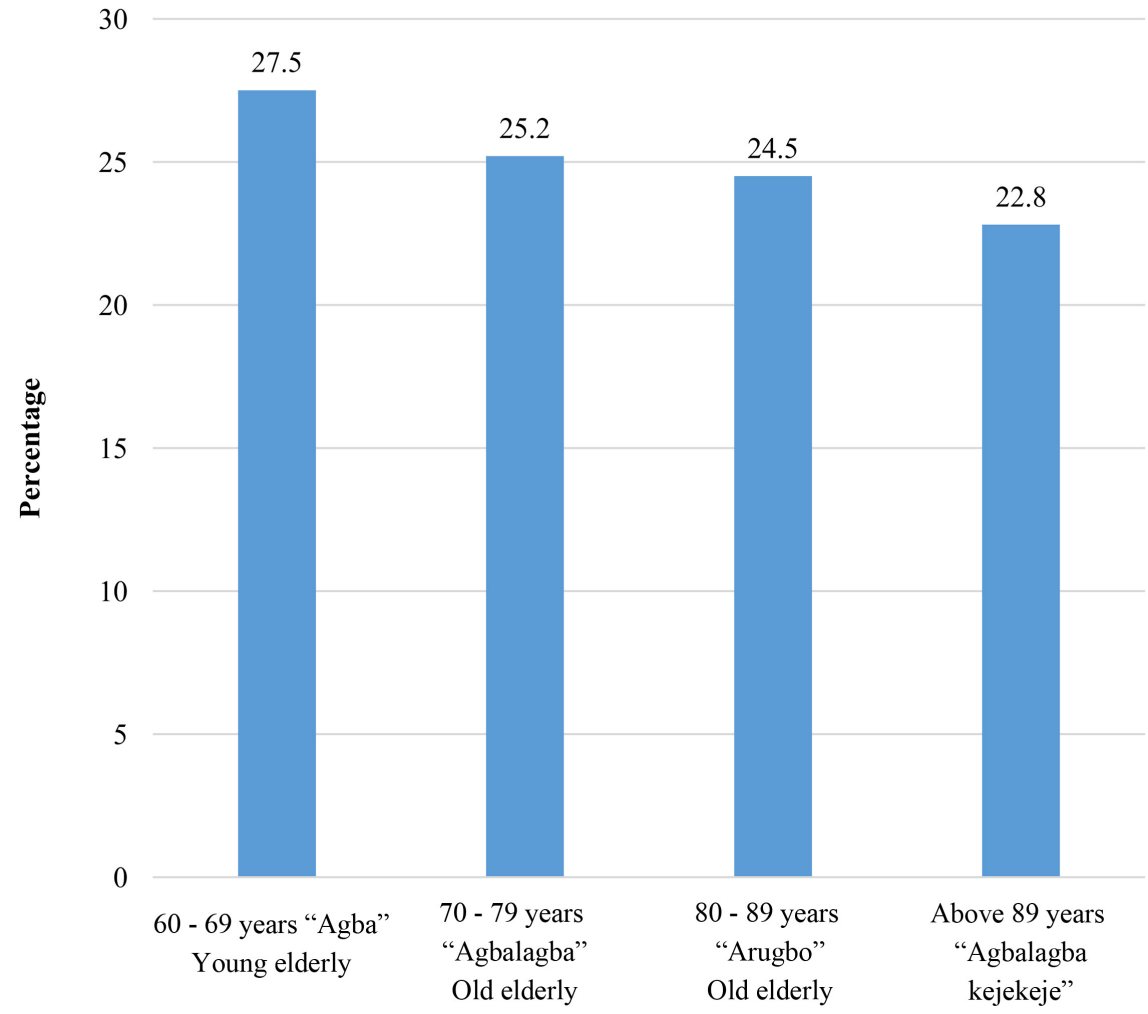

Figure 1. Yoruba social construction of elderly. 
oldest elderly (Agbalagbakejekeje). Narratives from the participants indicate that MS pain was perceived as parts of the attributes of growing older. Participants described the experiences of MS pain by age categories. Participants also expressed less fear on MS pain since it was perceived as normal experience for the elderly. This was expressed in an interview:

The way individual elderly think about the cause of MS pain differs, most especially, the way agba will perceive the cause of MS pain would be different from how agbalagba or arugbo would look at it. Arugbo often think of "going home peacefully" that is peaceful death, so the issue of bodily pain may not be their major concerns because they have lived with it for so long (IDI, Male Elderly, Ago-Are).

\subsection{Perceived Causes of Musculoskeletal Pain (MS Pain) Experiences}

The respondents' perception about the causes of MS pain was sourced and presented in Table 2. Factors such as the individual's occupation history, factors attributed to aging process, history of injury/accident, and change in individual's food intake were the perceived causes. Occupational hazard and related issues were the common factors perceived by most of the respondents whose pain experiences were located in their necks (78.8\%), pain in their shoulders (94.1\%), and pain in their elbows (96.0\%). Old age factors were perceived as the cause of MS pain experience in the writs/hands (27.9\%), while four-fifth $(80 \%)$ of the respondents who had pain in their upper back/lower neck perceived that it was caused by past work life history. Other perceived causes are shown in Table 2. In all, occupational factors were more perceived as the causes of MS pain at the

Table 2. Distribution of respondents on perceived reasons on MS pain locations.

\begin{tabular}{lcccc}
\hline & & \multicolumn{2}{c}{ Perceived Reasons for having MS Pain } \\
\cline { 3 - 5 } \multicolumn{1}{c}{ MS Pain locations } & $\begin{array}{c}\text { Frequency } \\
(\%)\end{array}$ & $\begin{array}{c}\text { History of } \\
\text { occupation } \\
(\%)\end{array}$ & $\begin{array}{c}\text { Due to } \\
\text { aging (\%) }\end{array}$ & $\begin{array}{c}\text { History of } \\
\text { injury/accident } \\
\text { (\%) }\end{array}$ \\
\hline Neck & $156(6.5)$ & $123(78.8)$ & $33(21.2)$ & - \\
Shoulders & $320(13.3)$ & $301(94.1)$ & $18(5.6)$ & - \\
Elbow & $50(2.1)$ & $48(96.0)$ & $2(4.0)$ & - \\
Wrists/hands & $68(2.8)$ & $49(72.1)$ & $19(27.9)$ & - \\
Upper back & $425(17.6)$ & $340(80.0)$ & $84(19.8)$ & $1(0.2)$ \\
Lower back & $416(17.3)$ & $384(92.3)$ & $32(7.7)$ & - \\
One or both hips/thighs & $254(10.5)$ & $236(92.9)$ & $10(3.9)$ & $8(3.1)$ \\
One or both knees & $472(19.6)$ & $353(74.8)$ & $106(22.5)$ & $13(2.8)$ \\
One or both ankles/feet & $249(10.3)$ & $202(81.1)$ & $32(12.9)$ & $15(6.0)$
\end{tabular}


various body locations of the respondents. In the same manner, history of occupation, and aging were the major perceived causes of musculoskeletal pain highlighted in the interviews among elderly. One traditional healer corroborates:

You see, when you are young, you can do whatever job you want to do without any physical hindrance. Some of these jobs could even take a lot of your energy away but you would not border because you are still young. Majority of the elderly had engaged themselves in several hard labour work like bricklaying, and farming work with hoes and cutlasses in the past. Believe me sincerely, there is no way tissues, muscles and bones of such elderly would not "demand for it" when the time comes at old age (KII, Traditional healer, Oyo Town).

\subsection{Patterns of MS Pain among the Elderly}

Pattern of MS pain was established among the elderly. Table 3 shows that $6.5 \%$ respondents identified neck as their pain location, out of which $78.2 \%$ respondents reported acute neck pain, while $7.1 \%$ had chronic neck pains. Also, among the $13.3 \%$ respondents who experienced pain on shoulders, seven often (73.8\%) had pain at their right shoulder only, 5.3\% had pain at their left shoulder only, while one-fifth (20.9\%) respondents experienced pain at both shoulders. Almost nine often (89.1\%) respondents experienced acute pain, while one-tenth $(10.6 \%)$ experienced sub-acute pain. Slightly above average $(52.0 \%)$ of the respondents

Table 3. Distribution of respondents on patterns of MS pain.

\begin{tabular}{|c|c|c|c|c|c|}
\hline \multirow[b]{2}{*}{$\begin{array}{l}\text { Body location of } \\
\text { MS Pain }\end{array}$} & \multirow[b]{2}{*}{$\begin{array}{c}\text { Frequency } \\
(\%)\end{array}$} & \multicolumn{3}{|c|}{ MS Pain Duration } & \multirow[t]{2}{*}{$\mathrm{X}^{2}$} \\
\hline & & $\begin{array}{c}\text { Acute } \\
(\%)\end{array}$ & $\begin{array}{c}\text { Sub-acute } \\
(\%)\end{array}$ & $\begin{array}{c}\text { Chronic } \\
\text { (\%) }\end{array}$ & \\
\hline Neck & $156(6.5)$ & $122(78.2)$ & $23(14.7)$ & $11(7.1)$ & - \\
\hline Shoulders & $320(13.3)$ & $285(89.1)$ & $34(10.6)$ & $11(0.3)$ & 0.000 \\
\hline \multicolumn{6}{|l|}{ Right shoulder-236 (73.8\%) } \\
\hline \multicolumn{6}{|l|}{ Left shoulder-17 (5.3\%) } \\
\hline \multicolumn{6}{|l|}{ Both shoulders-67 (20.9\%) } \\
\hline Elbow & $50(2.1)$ & $24(48.0)$ & $26(52.0)$ & - & 0.411 \\
\hline \multicolumn{6}{|l|}{ Right elbow-26 (52.0\%) } \\
\hline \multicolumn{6}{|l|}{ Both elbows-24 (48.0\%) } \\
\hline Wrists/hands & $68(2.8)$ & $41(60.3)$ & $26(38.2)$ & $1(1.5)$ & \\
\hline Right wrists/hand-41 (60.3\%) & & & & & 0.010 \\
\hline \multicolumn{6}{|l|}{ Both wrists-27 (39.7\%) } \\
\hline Upper back & $425(17.6)$ & $239(56.2)$ & $122(28.7)$ & $64(15.1)$ & 0.000 \\
\hline Lower back & $416(17.3)$ & $257(61.8)$ & $103(24.8)$ & $56(13.5)$ & 0.000 \\
\hline One or both hips/thighs & $254(10.5)$ & $88(34.6)$ & $146(57.5)$ & $20(7.9)$ & 0.004 \\
\hline One or both knees & $472(19.6)$ & $198(41.9)$ & $235(49.8)$ & $39(8.3)$ & 0.004 \\
\hline One or both ankles/feet & $249(10.3)$ & $96(38.6)$ & $117(47.0)$ & $36(14.5)$ & 0.000 \\
\hline
\end{tabular}


who had pain at their elbow experienced it in the right elbow, while $48.0 \%$ experienced pain at both elbows. Three of five (60.3\%) respondents who had wrists/hands pain experienced it in their right wrists/hands. Overall, $52.0 \%$ respondents with elbow pain had sub-acute pain, while $60.3 \%$ respondents with wrists/hands pain had acute pain. The combination of upper back pain and lower back pain revealed that one-third (34.9\%) of the respondents experienced back pain in general. Back pain has the highest prevalence rate in the purview of MS pain locations among the respondents.

However, this study showed that pain in either one or both knees location ranked highest as reportedly experienced by two-fifth (19.6\%) of the respondents. Chronic MS pain was reported for upper back and lower back, while the narratives indicated elderly use of "asapo" for treatment of MS pain of various locations in the body. This was also reported by the health officers, with concerns about abuse of drugs used for pain relief by the elderly:

MS pain among elderly has not often been well recognised or adequately treated in this community. The assessment of pain for the elderly is complicated in this community by series of factors; presence of other chronic conditions, use of multi-drug treatment that can interfere with the pain mechanisms and the presence of multiple causes of pain. Most time, these elderly use different drugs over-the-counter in as much they heard that the drugs are for pain-relief without knowing the side effects of such drugs in their bodies (KII, the most senior health officer, Ilora Health Centre).

\subsection{Perceived Causes of Musculoskeletal Pain and Age Cohort}

Clearly, Table 4 showed that the hard work experiences of the elderly at younger age were mostly perceived the cause of MS pain among the respondents. Data also indicate that the more elderly grows older the less they hold on to the perceived factor that caused pain. Other factors attributed to the cause include; "sleeping bed", "types of food intake", and "due to past accident experience". However, MS pain was considered "aisanawonagbalagba" (ailment of the elderly people) as indicated in the narratives of interviews.

\subsection{Influence of Musculoskeletal Pain Experiences on Elderly Activities}

Musculoskeletal pain was reported as having negative effect on the daily activities of the elderly people. The effects were shared as affecting different activities of the elderly, hence, $22.5 \%$ of the elderly were unable to move around, $19.5 \%$ were disturbed from deep sleep, while $15.9 \%$ respondents recalled that their inability to stand well and upright was as a result of MS pain on them. Also, 13.9\% of the respondents were unable to worship effectively at their churches or mosques due to the experience of MS pain, $13.8 \%$ reported that they were depressed as a result of MS pain experiences, $7.0 \%$ complained that the effect of MS pain on them resulted in their inability to eat well, 3.4\% reported that MS 
Table 4. Association between the perceived causes of MS pain and age cohort $(\mathrm{N}=1231)$.

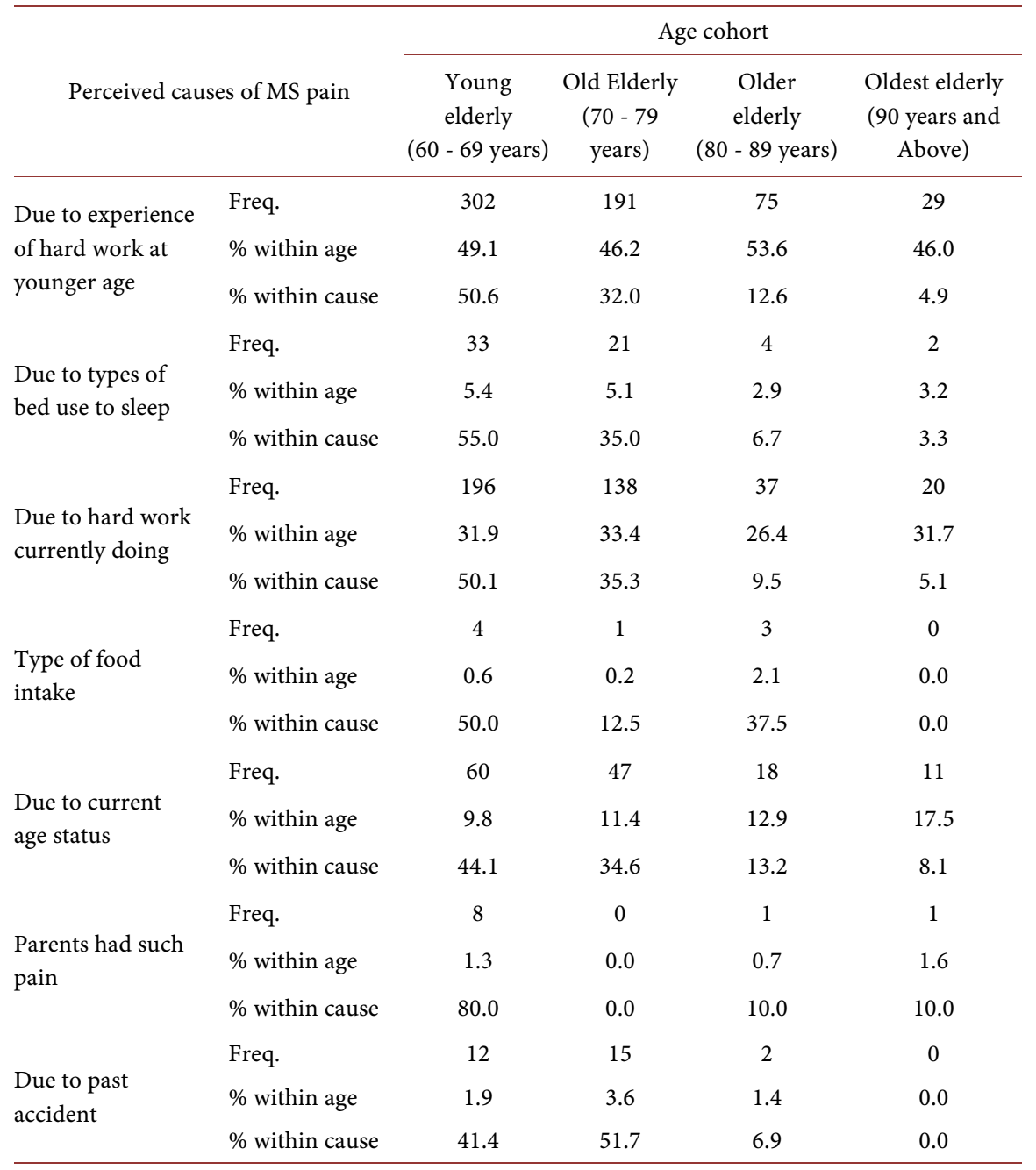

$\mathrm{X}^{2}=0.038, \mathrm{Df}=6, \mathrm{p}$-value $=0.05$.

pain led them to experience general body weakness, while $4.0 \%$ respondents fell into the category of having headache, feeling cold and having eyesight problem.

\subsection{Social Supports to Musculoskeletal Pain}

The relevance of social support as determinant of MS pain management is documented. Table 5 shows the rate of expected informational supports and the actual support rates received from various sources such as from the spouse, children, relatives, friends and community. Other sources include religious sects, social association, government organisation and non-governmental organisations. In all, while the support received from other sources were more than the expected, only the spouse did not provide supports to the expectation as shown in Table 5.

\subsection{Coping Strategies with Musculoskeletal Pain}

Strategies, ranging from massaging, getting drugs from the chemists, use of hot 
Table 5. Distribution of informational support on MS pain drug use.

\begin{tabular}{|c|c|c|c|c|c|}
\hline \multirow{2}{*}{\multicolumn{2}{|c|}{ Sources of Informational support }} & \multicolumn{4}{|c|}{ Information on Pain Drug Use } \\
\hline & & \multicolumn{2}{|c|}{ Expected } & \multicolumn{2}{|c|}{ Received } \\
\hline & & Frequency & Percent & Frequency & Percent \\
\hline \multirow{2}{*}{ Spouse } & No & 717 & 56.0 & 833 & 65.1 \\
\hline & Yes & 563 & 44.0 & 447 & 34.9 \\
\hline \multirow{2}{*}{ Children } & No & 808 & 63.1 & 628 & 49.1 \\
\hline & Yes & 472 & 36.9 & 652 & 50.9 \\
\hline \multirow{2}{*}{ Relatives } & No & 996 & 77.8 & 897 & 70.1 \\
\hline & Yes & 284 & 22.2 & 383 & 29.9 \\
\hline \multirow{2}{*}{ Friends } & No & 1166 & 91.1 & 1118 & 87.3 \\
\hline & Yes & 114 & 8.9 & 162 & 12.7 \\
\hline \multirow{2}{*}{ Community } & No & 1234 & 96.4 & 1148 & 89.7 \\
\hline & Yes & 46 & 3.6 & 132 & 10.3 \\
\hline \multirow{2}{*}{ Religious Sect. } & No & 1177 & 92.0 & 1152 & 90.0 \\
\hline & Yes & 103 & 8.0 & 128 & 10.0 \\
\hline \multirow{2}{*}{ Social Association } & No & 1220 & 95.3 & 1181 & 92.3 \\
\hline & Yes & 60 & 4.7 & 99 & 7.7 \\
\hline \multirow{2}{*}{$\begin{array}{l}\text { Governmental } \\
\text { Organizations }\end{array}$} & No & 1248 & 97.5 & 1176 & 91.9 \\
\hline & Yes & 32 & 2.5 & 104 & 8.1 \\
\hline \multirow{2}{*}{$\begin{array}{l}\text { Non-Governmental } \\
\text { Organizations }\end{array}$} & No & 1232 & 96.3 & 1200 & 93.8 \\
\hline & Yes & 48 & 3.8 & 80 & 6.3 \\
\hline
\end{tabular}

water or traditional medicine, were adopted to cope with MS pain. Data indicate that about one-third (32.6\%) of the respondents massaged, bathed with warm water, used pain killer and herbs together in coping with MS pain, $14.5 \%$ respondents visited chemist stores for complaints and treatment, while $7.4 \%$ respondents massaged the affected part. Also $4.6 \%$ respondents used hot water and pain killer balm, 3.7\% respondents used leftover pain-killer drugs during previous episode, $4.5 \%$ respondents used traditional medicine, while $30.5 \%$ respondents did not do anything to cope with MS pain.

\section{Discussion}

Half of the respondents in this study did not have any formal education. This was also noted in the National Population Commission (NPC) data where it was reported that $66.5 \%$ of people of age 60 years and above did not receive any formal education in Oyo State [25]. Clearly, the population of the elderly reported in NPC [25] as having no formal education was still higher by $15 \%$ than the elderly in this study. The global delineation of elderly age has three categorisation vis-a-vis "young old" (60 - 74 years old), "old old" (75 - 84 years), and "oldest old" (85 years and above) [28] [29]. In this study, the narratives of the participants on the construction of the elderly identified four categorisation into 
"Agba" (young elderly) 60 - 69 years; "Agbalagba" (old elderly) 70 - 79 years; "Agbalagbakejekeje" (older elderly) 80 - 89 years, and "Arugbo" (oldest elderly) above 89 years old. The period of $A g b a$, described as the entry point into elderly category, is estimated to tally with the ideal period of retirement (which is 60-65 years) in Nigeria. This period may coincide with that of retirement age in many countries of the world. Although there are no global agreed standard numerical criteria, the United Nations put 60 years as cut off [28], while chronological age is often associated with age of retirement [28] in many countries. Agbalagba period is described as the time when one begins to depreciate in capacity and with less commitment/participation in activities. The biological aging dimension, which according to Hooyman and Kiyak [30], indicates a reduction in bone density and visual acuity, which are normal parts of physiological changes of growing older, is in line with the present findings. Agbalagbakejekeje and Arugbo categories are period of time when individuals begin to act like "children", completely dependent on other people around for supports to actualise many tasks. A previous study also observed that psychological aging indicates changes in mental functioning and personality, while social aging refers to changes that occur in person's roles and relationship with others [30]. In such cases of social aging, a young person of age 40 may function as "old" due to enduring lifetime of poverty, malnutrition and heavy labour, while privileged people may remain free of health challenges that often accompany ageing until they attain the age of 70 years or 80 years [6]. The social definition may depict people from a particular age group referring to a senior in age group as old [31] and change in social role is predominant means of defining old age in cultural analysis.

Occupational history is one of the major factors that cause MS pain not only due to the type of jobs elderly did at early stage of life, but also common to active younger adults. For instance, a study among nurses found that low back pain was a major occupational problem reported by the professional group [32], hence, confirming the experiences of musculoskeletal pain explainable in terms of occupational-specific of the individuals [33].

Back pain was reported by more than half of the participants in this study. Globally, back pain is observed to have caused more disability than any other health condition [34]. Back pain is also one of the common health conditions for which patients in high-income countries seek medical attention [35]. In Italy for instance, $32 \%$ of older adults of 65 years and above complained of back pain [36], while back pain was reported by 36 percent of community-dwelling elderly of 70 - 79 years old in the United States [37]. The Global Burden of Disease Study in 2010 ranked low back pain as the condition with the highest number of years lived with disability (YLDs) and sixth in terms of disability-adjusted life years [38].

This present study found association between age cohort of elderly and perceived causes of MS pain $\left(\chi^{2}=0.038\right)$. Findings in this study indicate that the age cohort of respondents affects the ways elderly perceived the cause of MS pain. 
Also, almost half of young elderly and $46.2 \%$ of old elderly perceived the hard work experience at younger age as the cause of MS pain. Whereas, body ache/joint pain was perceived as signs/symptoms of malaria by mothers of children under age five years [39].

The effect of MS pain could cause social isolation, weak spiritual life, sense of despair, regret, loss of the meaning of life and a feeling of being forsaken by both man and even God, as observed by Andruszkiewicz, Basinska, et al., [40]. Findings in this study also showed that the experiences of MS pain on aging process significantly impairs functioning of individual elderly in various ways. For instance, this study shows that MS pain can impair cognitive functioning, lead to mood changes (such as increase anxiety and depression), deepens social withdrawal [41], disturbs sleep and increases disability and risk of falling down [42], which could in turn result inlower quality of life [43]. Whereas MS pain is not a natural component of the aging process for elderly [44], some concerns suggest that pain threshold in older people is higher and therefore older people can bear more extreme stimuli at which pain begins to be felt [45]. Getting away from this, chronic pain especially, is regarded as a stressful factor not only for elderly but also for individual sufferers of pain and hence destroys their psychosocial balance for coping, as observed by Andruszkiewicz et al., [40].

\section{Limitation of the Study}

This is a community survey and it has relied mainly on verbal reporting of the elderly persons who reportedly experienced musculoskeletal pain. The age of the respondents was also known through self-reporting. However, questions that revolve around pain experience were the main concern of the study and were posed to the participants. Participants indicated the different locations in the body with MS pain experience. Future study may trace participants through a review of hospital register. Such register would contain details including age of the participants.

\section{Conclusion}

This study has documented the social dimensions of musculoskeletal pain and its influence on the aging process in its dimensional form among the elderly of Oyo State. At the age, large majority of the elderly received less than thirty thousand naira $(<\$ 100)$ a month, while they incurred more expenditure on health care without having enrolment with health insurance scheme to take care of their health expenditure. Signs of aging process and previous occupational experience were perceived as the cause of MS pain. The elderly reportedly experienced MS pain in four different body locations including the knees, upper back, lower back and shoulders with resulting effects such as inability to move around, inability to have deep sleep and depression propelled by the experience of MS pain. These findings show some trends and provide a basis for policy relevance recommendation to design special health care and social services 
schemes for the elderly in Nigeria. Partnership between government and viable private health providers at various communities in Nigeria would enhance easy access to health care services by the elderly.

\section{Acknowledgements}

All the efforts of the participants in giving their time to participate in this study are highly appreciated. The effort of field staff in data collection is also appreciated. The main study received a $\mathrm{PhD}$ Thesis Grant from LAPO Institute.

\section{Conflicts of Interest}

The authors declare no conflicts of interest regarding the publication of this paper.

\section{References}

[1] Health and Safety Executive (2012) Musculoskeletal Disorders 2011-2012. http://www.hse.gov.uk/statistics/overall/hssh1213.pdf

[2] World Health Organisation (2009) Global Health Risks: Mortality and Burden of Disease Attributable to Selected Major Risks. https://apps.who.int/iris/handle/10665/44203

[3] Langley, P.C. (2011) The Prevalence, Correlates, and Treatment of Pain in the European Union. Current Medical Research and Opinion, 27, 463-480. https://doi.org/10.1185/03007995.2010.542136

[4] United Nations Population Fund (UNFPA) (2012) The State of World Population. http://www.unfpa.org

[5] Ogunshola, F. (2015) Why Need National Aging Policy in Nigeria. People's Daily. https://peoplesdaily.com

[6] World Health Organization (2007) Women, Ageing and Health: A Framework for Action. Focus on Gender. https://www.who.int/ageing/publications/Women-ageing-health-lowres.pdf

[7] National Academy of Science (2011) Relieving Pain in America: A Blueprint for Transforming, Prevention, Care, Education, and Research. National Academies Press, Washington DC.

[8] National Institute for Health and Clinical Excellence (NICE) (2008) Osteoarthritis: The Care and Management of Osteoarthritis in Adults. In: Clinical Guideline, National Institute for Health and Clinical Excellence, London.

[9] Robb, M.J.M. and Mansfield, N.J. (2007) Self-Reported Musculoskeletal Problems amongst Professional Truck Drivers. Ergonomics, 50, 814-827. https://doi.org/10.1080/00140130701220341

[10] Okunribido, O.O., Magnusson, M. and Pope M.H. (2008) The Role of Whole Body Vibration, Posture and Manual Materials Handling as Risk Factors for Low Back Pain in Occupational Drivers. Ergonomics, 51, 308-329. https://doi.org/10.1080/00140130701637262

[11] Woolf, A.D. and Pfleger, B. (2003) Burden of Major Musculoskeletal Conditions. Bulletin of the World Health Organisation, 81, 646-656. https://www.who.int

[12] Centers for Disease Control and Prevention (CDC) (2013) The State of Aging and Health in America. Atlanta, GA. 
[13] Tsang, A., Von Korff, M., Lee, S., Alonso, J., Karam, E., Angermeyer, M.C. and Watanabe, M. (2008) Common Persistent Pain Conditions in Developed and Developing Countries: Gender and Age Differences and Comorbidity with Depression-Anxiety Disorders. The Journal of Pain, 9, 883-891.

[14] Department of Health (2008) End of Life Care Strategy: Promoting High Quality Care for All Adults at the End of Life. Department of Health, London.

[15] Lillie, A.K., Read, S., Mallen, C., Croft, P. and McBeth, J. (2013) Musculoskeletal Pain in Older Adults at the End-of Life: A Systematic Search and Critical Review of the Literature with Priorities for Future Research. BMC Palliative Care, 12, 27. http://www.biomedcentral.com/1472-684X/12/27

[16] Kelsall, H.L., McKenize, D.P., Forbes, A.B., Roberts, M.H., Urquhart, D.M. and Sim, M.R. (2014) Pain-Related Musculoskeletal Disorders, Psychological Comorbidity, and the Relationship with Physical and Mental Well-Being in Gulf War Veterans. Pain, 155, 685-692. https://doi.org/10.1016/j.pain.2013.12.025

[17] Guyer, J.I. and Salami, K.K. (2013) Life Courses of Indebtedness in Rural Nigeria. In: Lynch, C. and Danely, J., Eds., Transitions and Transformations: Cultural Perspectives on Aging and the Life Course, Berghahn Books, New York.

[18] Pew Research Centre (2014) Attitudes about Aging: A Global Perspective. https://www.pewresearch.org

[19] Isiugo-Abanihe, U.C. and Wahab, E.O. (2009) Epistemological Advances in Studying the Demography of Ageing. The Anthropologist, 11, 265-270.

https://doi.org/10.1080/09720073.2009.11891114

[20] Wahab, E.O. (2013) Pension Challenges Facing the Older Persons in Nigeria. European Scientific Journal, 9, No, 8.

[21] Omobowale, A.O. (2014) An Ethnographic Textual Analysis of Aging and the Elders in South Western Nigeria. Canadian Journal of Sociologyl Cahiers Canadiens De Sociologue, 39, 211-230. https://journals.library.ualberta.ca/cjs/index.php/CJS/article/view/22237

[22] Salami, K.K. (2014) Ex-Servicemen and the Life Courses of Retirement in Ibadan, Nigeria. The Nigerian Journal of Sociology and Anthropology, 12, 213-232.

[23] Jensen, M.P., Moore, M.R., Bockow, T.B., Ehde, D.M. and Engel, J.M. (2011) Psychosocial Factors and Adjustment to Persistent Pain in Persons with Physical Disabilities: A Systematic Review. Archives of Physical Medicine \& Rehabilitation, 92, 146-160. https://doi.org/10.1016/j.apmr.2010.09.021

[24] Kitayuguchi, J., Kamada, M., Okada, S., Kamioka, H. and Mutoh, Y. (2015) Association between Musculoskeletal Pain and Trips or Falls in Rural Japanese Community-Dwelling Older Adults: A Cross-Sectional Study. Geriatrics \& Gerontology International, 15, 54-64. https://doi.org/10.1111/ggi.12228

[25] National Population Commission (2006) Population and Housing Census. Priority Table Volume IV, Population Distribution by Age and Sex. National Population Commission 2010, Federal Republic of Nigeria, Abuja.

[26] Braun, V. and Clarke, V. (2006) Using Thematic Analysis in Psychology. Qualitative Research in Psychology, 3, 77-101. https://doi.org/10.1191/1478088706qp063oa

[27] Cornish, F., Gillespie, A. and Zittoun, T. (2014) Collaborative Analysis of Qualitative Data. In: Flick, U., Ed., The SAGE Handbook of Qualitative Data Analysis, Sage Publications, London, 79-93. https://doi.org/10.4135/9781446282243.n6

[28] World Health Organization (WHO) (2003) Burden of Major Musculoskeletal Conditions. Special Theme-Bone and Joint Decade 2000-2010. Bulletin of the WHO, 81, 
646-656.

[29] Community and Family Health Division Office of Rural Health and Primary Care and Office of Public Health Practice (MDH) (2006) Creating Healthy Communities for an Aging Population. A Report of a Joint Rural Health Advisory Committee and State Community Health Services Advisory Committee Work Group.

[30] Hooyman, N.R. and Kiyak, H.A. (2011) Social Gerontology: A Multidisciplinary Perspective. 9th Edition. Pearson, New York.

[31] Ezeh, A., Chepngeno, G., Kasiira, A.Z. and Woubalem, Z. (2006) The Situation of Older People in Poor Urban Settings: The Case of Nairobi, Kenya. In: Cohen, B. and Menken, J., Eds., Aging in Sub-Saharan Africa: Recommendations for Furthering Research National Research Council, The National Academies Press, Washington DC, 189-213.

[32] Boughattas, W., El Maalel, O., Maoua, M., Bougmiza, I., Kalboussi, H., Brahem, A., Chatti, S., Mahjoub, F. and Mrizak, N. (2017) Low Back Pain among Nurses: Prevalence and Occupational Risk Factors. Occupational Diseases and Environmental Medicine, 5, 26-37. https://doi.org/10.4236/odem.2017.51003

[33] Park, J., Kim, S.G., Park, J., Han, B., Kim, B.E. and Kim, Y. (2017) Hazards and Health Problems in Occupations Dominated by Aged Workers in South Korea. Annals of Occupational and Environmental Medicine, 29, 27. https://doi.org/10.1186/s40557-017-0177-9

[34] Stewart, W.J., Ng, N., Peltzer, K., Yawson, A., Biritwum, R., Maximova, T., et al. (2015) Risk Factors and Disability Associated with Low Back Pain in Older Adults in Low- and Middle-Income Countries. Results from the WHO Study on Global AGEing and Adult Health (SAGE). PLoS ONE, 10, e 0127880. https://doi.org/10.1371/journal.pone.0127880

[35] Manek, N.J. and MacGregor, A.J. (2005) Epidemiology of Back Disorders: Prevalence, Risk Factors, and Prognosis. Current Opinion in Rheumatology, 17, 134-140.

[36] Cecchi, F., Debolini, P., Molino Lova, R., Macchi, C., Bandinelli, S., Bartali, B., et al. (2006) Epidemiology of Back Pain in a Representative Cohort of Italian Persons 65 Years of Age and Older: The InCHIANTI Study. Spine, 31, 1149-1155.

[37] Fejer, R. and Ruhe, A. (2012) What Is the Prevalence of Musculoskeletal Problems in the Elderly Population in Developed Countries? A Systematic Critical Literature Review. Chiropractic \& Manual Therapies, 20, 31. https://doi.org/10.1186/2045-709X-20-31

[38] Hoy, D., March, L., Brooks, P., Blyth, F., Woolf, A., Bain, C., et al. (2014) The Global Burden of Low Back Pain: Estimates from the Global Burden of Disease 2010 Study. Annals of the Rheumatic Diseases, 73, 968-974. https://doi.org/10.1136/annrheumdis-2013-204428

[39] Adeneye, A.K., Jegede, A.S., Mafe, M.A. and Nwokocha, E.E. (2013) Community Perceptions and Home Management of Malaria in Selected Rural Communities of Ogun State, Nigeria. International Journal of Malaria Research and Reviews, 1, 22-34. http://www.resjournals.org/IJMR/PDF/2013/Aug/Adeneye et al.pdf

[40] Andruszkiewicz, A., Basińska, M.A., Felsmann, M., Mariola Banaszkiewicz, M., Marzec, A. and Kędziora Kornatowska, K. (2017) The Determinants of Coping with Pain in Chronically Ill Geriatric Patients-The Role of a Sense of Coherence. Clinical Interventions in Aging, 12, 315-323. https://doi.org/10.2147/CIA.S118136

[41] Davis, M.P. and Srivastava, M. (2003) Demographics, Assessment and Management of Pain in the Elderly. Drugs \& Aging, 20, 23-57.

https://doi.org/10.2165/00002512-200320010-00003 
[42] Pasero, C. and McCaffrey, M. (2005) Pain Control: Comfort-Function Goals. A Way to Establish Accountability for Pain Relief. American Journal of Nursing, 104, 77-78+81. https://doi.org/10.1097/00000446-200409000-00037

[43] Sullivan, M., Tanzer, M., Stanish, W., et al. (2009) Psychological Determinants of Problematic Outcomes Following Total Knee Arthroplasty. Pain, 143, 123-129. https://doi.org/10.1016/j.pain.2009.02.011

[44] American Geriatric Society (2009) American Geriatric Society. Panel on the Pharmacological Management of Persistent Pain in Older Persons: Pharmacological Management of Persistent Pain in Older Persons. Journal of the American Geriatrics Society, 37, 1331-1346. https://doi.org/10.1111/j.1532-5415.2009.02376.x

[45] Benedetti, F., Vighetti, S., Ricco, C., et al. (1999) Pain Threshold and Tolerance in Alzheimer's Disease. Pain, 80, 377-382. 